\title{
Antitumor Activity of a Novel Fibroblast Growth Factor Receptor Inhibitor for Intrahepatic Cholangiocarcinoma
}

Chiara Raggi, ${ }^{\dagger}$ Karim Fiaccadori, ${ }^{*}$ Mirella Pastore, ${ }^{\dagger}$ Margherita Correnti, ${ }^{*}$ Benedetta Piombanti, ${ }^{\dagger}$ Elisa Forti, ${ }^{*}$ Nadia Navari, Giovanni Abbadessa, ${ }^{\ddagger}$ Terence Hall, ${ }^{\ddagger}$ Annarita Destro, ${ }^{\S}$ Luca Di Tommaso, ${ }^{\S \mathbb{\top}}$ Massimo Roncalli, ${ }^{\S \pi}$ Fanyin Meng, Shannon Glaser, Elisabetta Rovida, ${ }^{* *}$ Caterina Peraldo-Neia, ${ }^{\dagger \dagger}$ Paula Olaizola, ${ }^{\ddagger \dagger}$ Jesus M. Banales, ${ }^{\ddagger}$ Alessio Gerussi,

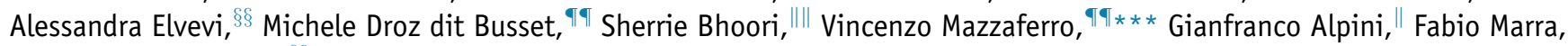
and Pietro Invernizzi* ${ }^{\star} \S$

From the Humanitas Clinical and Research Center, ${ }^{*}$ Rozzano, Italy; the Departments of Experimental and Clinical Medicine ${ }^{\dagger}$ and Experimental and Clinical Biomedical Sciences, ** University of Florence, Florence, Italy; the Clinical Development Department ${ }^{\ddagger}$ ArQule, Inc., Burlington, Massachusetts; the Pathology Unit,$^{\S}$ Humanitas Research Hospital, Rozzano, Italy; the University of Milan Medical School, ${ }^{\uparrow}$ Milan, Italy; the Department of Research, ${ }^{\|}$Central Texas Veterans Health Care System, Baylor Scott \& White Digestive Disease Research Center, Scott \& White Health, Department of Medical Physiology, Texas A\&M University, College of Medicine, Temple, Texas; the Cancer Genomics Laboratory, ${ }^{\dagger \dagger}$ Fondazione Edo and Elvo Tempia, Biella, Italy; the Department of Liver and Gastrointestinal Diseases, ${ }^{\ddagger}$ Biodonostia Research Institute, Donostia University Hospital, University of the Basque Country (Universidad del País Vasco/Euskal Herriko Unibertsitatea), Networked Biomedical Research Center for Hepatic and Digestive Diseases, Ikerbasque, San Sebastián, Spain; the Division of Gastroenterology and Center for Autoimmune Liver Diseases, ${ }^{\S \S}$ San Gerardo Hospital, Department of Medicine and Surgery, University of Milan-Bicocca, Monza, Italy; Hepato-Pancreato-Biliary Surgery and Liver Transplantation ${ }^{\top \uparrow}$ and Gastroenterology and Liver Transplant Hepatology, "III IRCCS Foundation National Cancer Institute, Milan, Italy; and the Department of Surgery, *** University of Milan, Milan, Italy

Accepted for publication

June 18, 2019.

Address correspondence to Chiara Raggi, Ph.D., Universita' di Firenze, Largo Brambilla 3 (Firenze), Florence, Italy; or Pietro Invernizzi, Ph.D., M.D., Division of Gastroenterology and Center for Autoimmune Liver Diseases, San Gerardo Hospital, Department of Medicine and Surgery, University of MilanBicocca, Via Cadore 48, 20900 Monza (MB), Italy. E-mail: chiara. raggi@unifi.it or pietro.invernizzi@ unimib.it.
Fibroblast growth factor receptor 2 (FGFR2) might have an important role in the pathogenesis and biology of cholangiocarcinoma (CCA). We examined FGFR expression in CCA tumor specimens obtained from patients and CCA cell lines, and then determined the effects of the novel FGFR inhibitor, derazantinib (DZB; formally, ARQ 087), which is currently in clinical phase 2 trials for intrahepatic CCA. DZB inhibited the growth of CCA cell lines in a dose-dependent manner, and extracellular signal-regulated kinase $1 / 2$ and AKT. It also activated apoptotic and cell growth arrest signaling. DZB reduced the in vitro invasiveness and the expression of key epithelial-mesenchymal transition genes. The in vitro data correlated with the expression of FGFRs in human CCA specimens by immunohistochemistry (FGFR1, 30\% positive; and FGFR2, 65\% positive) and the CCA cell lines assayed by Western blot analysis. These correlated in vitro studies suggest that FGFR may play an important role in the pathogenesis and biology of CCA. Our findings support the notion that FGFR inhibitors, like DZB, should be further evaluated at the clinical stage as targeted therapy for CCA treatment. (Am J Pathol 2019, 189: 2090-2101; https://doi.org/10.1016/j.ajpath.2019.06.007)
Cholangiocarcinoma (CCA) forms a highly heterogeneous group of malignant tumors arising from cholangiocytes located in the biliary epithelium. After hepatocellular carcinoma (HCC), CCA is the second most common liver malignancy in the United States and Western Europe. As there is no effective treatment for advanced CCA, it has a poor prognosis. ${ }^{1,2}$ In addition, its survival rate is low, and only $5 \%$ of these patients survive for 5 years after tumor development. ${ }^{3}$
Supported in part by the Scott \& White Dr. Nicholas C. Hightower Centennial Chair of Gastroenterology, a Veterans Affairs Research Career Scientist Award, the Central Texas Veterans Health Care System, the Italian Foundation of Cancer Research awards MFGA17588 (C.R.) and IG17786 (F.M.), and ArQule, Inc.

Disclosures: T.H. is an employee of ArQule, Inc (Burlington, MA).

The views expressed in this article are those of the authors and do not necessarily represent the views of the Department of Veterans Affairs. 
Surgical resection is the treatment for early-stage CCA, and this is frequently followed by chemotherapy or radiotherapy. However, post-resection 5-year survival is only $20 \%$ to $30 \%$. In most cases, CCA is diagnosed at an advanced, unresectable stage; and although chemotherapy improves the life quality of these patients, it is only a palliative treatment. ${ }^{4-6}$ Most patients with unresectable CCA will undergo a rapid clinical decline and usually die within 12 months from symptom onset. To improve the outlook for patients with CCA, both clinical and bench science advances are imperative. ${ }^{4-9}$

The fibroblast growth factor receptors (FGFRs) represent a family of transmembrane proteins with intrinsic tyrosine kinase activity. Binding of fibroblast growth factors (FGFs) is necessary for FGFR activation. ${ }^{7}$ After ligand binding, FGFR dimerizes, and this leads to transphosphorylation of tyrosine residues and their activation. ${ }^{7-9}$ The receptor family has four closely related genes, FGFRs 1 to 4 , which are signals in the extracellular signal-regulated kinase (ERK) 1/2, STAT, and AKT effector pathways. ${ }^{710-12}$ FGFR signaling may play an important role in regulating CCA cell proliferation, survival, migration, invasion, angiogenesis, and tumor progression. ${ }^{13}$

Derazantinib (DZB) is a recently developed, orally bioavailable, ATP-competitive inhibitor of FGFRs 1 to 3. DZB has potent in vitro and in vivo inhibitory effects on a variety of FGFR-dependent human cancer cell lines and xenograft tumor models. ${ }^{14-18}$ More important, there is clinical proof of concept in intrahepatic CCA (iCCA), and a registrational phase 2 study in iCCA is ongoing for DZB (NCT03230318), which is sponsored by Basilea Pharmaceutica (Basel, Switzerland).

In this study, we determined the in vitro pharmacologic inhibitory functions of DZB on human CCA cell lines to assess its potential therapeutic use for cancer.

\section{Materials and Methods}

\section{Human Samples}

A total of 32 formalin-fixed, paraffin-embedded human liver tissue specimens were analyzed for the immunohistochemical expression of FGFR1 and FGFR2. All specimens were obtained after surgical resection and collected in the tissue bank at Humanitas Clinical Institute (Rozzano, Italy) in accordance with informed consent retrieved from patients and local ethics committee approval. The analyzed specimens included 19 samples of CCA, 10 samples of cirrhotic liver (hepatitis C virus positive) with superimposed $\mathrm{HCC}$, together with normal liver tissue $(n=3)$ as negative controls, which include the surrounding liver in resected metastasis from colorectal cancer $(n=2)$ and hepatic adenoma $(n=1)$. Normal liver tissue was obtained after partial hepatectomy for a solitary colorectal cancer metastasis. In these cases, FGFR 1 and 2 expression levels were evaluated in liver tissue distant from the metastasis. The histology of the primary tumors was reviewed by board-certified pathologists (A.D. and L.D.T.) experienced in liver tumors and classified according to the tumor-nodemetastasis staging system (Supplemental Table S1).
For the RT-PCR analysis of Fgfr RNA expression, the nonmalignant tissue counterpart adjacent to CCA tissue was collected at the time of surgery and, when suitable, used as control. Frozen tumor tissues from CCA patients $(n=33)$ [Humanitas Clinical Institute, $n=13$; Institute of Candiolo (Candiolo, Italy), $n=3$; and Donostia University Hospital (San Sebastián, Spain), $n=17$ ] were examined. Surrounding normal human tissues $(n=18)$ were also tested. The RT-PCR cohort was independent from the cohort in which immunohistochemical expression was performed. Correlation analysis between $\mathrm{Fg} f \mathrm{r}$ gene expression and tumor grade was performed with 26 of 33 cases that had a clear $\mathrm{G}_{1} / \mathrm{G}_{2} / \mathrm{G}_{3}$ status presented in Supplemental Table S2. Research protocols were approved by the Clinical Research Ethics Committees of the supporting institutions, and all patients signed written consents for the use of their samples for biomedical research.

\section{Cell Cultures and Reagents}

HUCCT1 and CCLP1 cells from intrahepatic bile duct cancer tissues were a kind gift from Dr. Anthony J. Demetris (University of Pittsburgh, Pittsburgh, PA); cell lines were cultured as described previously. ${ }^{19-21}$ The human nonmalignant cholangiocyte cell line (normal human cholangiocytes) was provided by Dr. Jesus M. Banales (Donostia University Hospital, San Sebastián, Spain). ${ }^{22}$ The primary human hepatocytes were purchased from Sigma (St. Louis, MO). The HCC cell lines (PLC/PRF/5, Huh7, and HepG2) (a kind gift from Dr. Snorri S. Thorgeirsson, Valentina Factor, and Elizabeth A. Conner, Center for Cancer Research, National Cancer Institute, NIH, Bethesda, MD) were cultured as described previously. ${ }^{23}$ The stable HUCCT1 cell line overexpressing FGFR2-periphilin 1 (PPHLN1) fusion protein ${ }^{24}$ was kindly provided by Prof. Vincenzo Mazzaferro (IRCCS Foundation National Cancer Institute, Milan, Italy). DZB was kindly provided by ArQule, Inc. (Burlington, MA). The anti-FGFR inhibitors, TG10052 hydrochloride, ENMD-2076, and ENMD-2076 tartrate were purchased from MedChemExpress (Princeton, NJ).

\section{Measurement of Cell Viability}

Cell lines were plated in 96-well plates at a concentration of 2000 cells/well and incubated for 2, 24, and 72 hours with different concentrations of ARQ $087(0.1,0.3,1,3$, and 10 $\mu \mathrm{mol} / \mathrm{L})$. The control solution consisted of $0.1 \%$ dimethyl sulfoxide. Cell viability was measured by MTT assay (Sigma), as previously described. ${ }^{25}$ Briefly, at the end of treatment, $10 \mu \mathrm{L}$ of MTT reagent was added to each well, and the plates were incubated at $37^{\circ} \mathrm{C}$ for an additional 2 hours. The absorbance was measured at $550 \mathrm{nmol} / \mathrm{L}$ using the ThermoScientific Multiskan FC microplate reader (Thermo Fisher Scientific, Waltham, MA). ${ }^{16}$

\section{Western Blot Analysis}

Cells were plated at a density of $10^{6}$ cells $/ 55-\mathrm{cm}^{2}$ plate dish. After 4 days, cells were treated with ARQ 087 at different 
concentrations $(0,0.3,3$, and $10 \mu \mathrm{mol} / \mathrm{L})$ for 2 hours and then stimulated with FGF7 (R\&D Systems, Minneapolis, MN) at $100 \mathrm{ng} / \mathrm{mL}$ for 15 minutes. Cells were also stimulated with FGF7 in the absence of ARQ 087 (0-) for use as a control. ${ }^{16}$

Cells were lysed at $4{ }^{\circ} \mathrm{C}$ with lysis buffer $(1 \%$ Triton X-100, $50 \mathrm{mmol} / \mathrm{L}$ Tris-HCl, $\mathrm{pH} 7.4,150 \mathrm{mmol} / \mathrm{L} \mathrm{NaCl}, 1 \mathrm{mmol} / \mathrm{L}$ EDTA, $1 \mathrm{mmol} / \mathrm{L}$ sodium orthovanadate, $2 \mathrm{mmol} / \mathrm{L}$ phenylmethylsulfonyl fluoride, and $1 \mathrm{mmol} / \mathrm{L}$ each of leupeptin and pepstatin). After 30 minutes of lysis, cellular extracts were centrifuged for 10 minutes at $12,000 \times g$, and the supernatant was used for Western blot analysis experiments, as detailed previously. ${ }^{26}$ Antibodies were used for Western blot analysis, according to the manufacturer's recommendations.

Immunoblots were incubated overnight at $4^{\circ} \mathrm{C}$ with primary antibody in $1 \%$ bovine serum albumin in $1 \times$ Dulbecco's phosphate-buffered saline. Rabbit monoclonal anti-FGF receptor 1 XP (number 9740; Cell Signaling Technology, Danvers, MA), rabbit monoclonal anti-FGF receptor 2 (number 11835; Cell Signaling Technology), mouse monoclonal anti-phosphorylated (phospho-)FGFR (Tyr-653/654; number 3476; Cell Signaling Technology), rabbit monoclonal anti-c-Myc (number 5605; Cell Signaling Technology), mouse monoclonal anti-phospho-AKT (Ser473; number 4051; Cell Signaling Technology), rabbit polyclonal anti-AKT (number 9272; Cell Signaling Technology), rabbit polyclonal anti-phospho-ERK1/2 (Thr202/Tyr204; number 9101; Cell Signaling Technology), mouse monoclonal antiERK 1/2 (sc-514302; Santa Cruz Biotechnology, Dallas, TX), rabbit polyclonal anti-Bcl-2 (ab7973; Abcam, Cambridge, UK), rabbit monoclonal anti-p27 Kip1 (number 3686; Cell Signaling Technology), rabbit monoclonal anti-poly (ADP-ribose) polymerase (number 9532; Cell Signaling Technology), rabbit polyclonal anti-cyclin D1 (number 2922; Cell Signaling Technology), rabbit polyclonal anti-phospho-p38 (Thr180/Tyr182)-R (sc-17852-R; Santa Cruz Biotechnology), rabbit polyclonal anti-p38a (sc535; Santa Cruz Biotechnology), rabbit polyclonal anti-Angio-1 (sc-8357; Santa Cruz Biotechnology), and rabbit polyclonal anti-FGF2 (sc-7911; Santa Cruz Biotechnology) antibodies were used. Immunoblots were then incubated with secondary antibody $\alpha$-rabbit/mouse (1:4000) in $1 \%$ bovine serum albumin in $1 \times$ Dulbecco's phosphate-buffered saline for 1 hour. Monoclonal anti- $\beta$-actin antibody, produced in mouse (A5441; Sigma), or monoclonal antivinculin antibody, produced in mouse (V9131; Sigma), was used as internal control $(1: 1000)$ in $1 \%$ bovine serum albumin in $1 \times$ Dulbecco's phosphate-buffered saline. The signal was quantified by chemiluminescence detection on an Image Quant Las4000 (GE Healthcare Life Sciences, Marlborough, MA), and subsequent analysis was performed with ImageJ software version 1 (NIH; http://imagej.nih.gov/ij).

\section{Cell Cycle and Apoptosis Analysis}

In total, 100,000 cells/well were seeded in multiwell dishes and exposed to the appropriate conditions. After medium removal,
$400 \mu \mathrm{L}$ of solution containing $50 \mu \mathrm{g} / \mathrm{mL}$ propidium iodide, $0.1 \% \mathrm{w} / \mathrm{v}$ trisodium citrate, and $0.1 \%$ Nonidet P-40 were added. Samples were then incubated for 30 minutes at $4{ }^{\circ} \mathrm{C}$ in the dark, and nuclei were analyzed with a FACSCanto flow cytometer (Becton Dickinson, Franklin Lakes, NJ). Gating was performed to exclude cellular debris. For the quantification of apoptosis, cells were resuspended in antibody-binding buffer (HEPES-buffered saline solution with $2.5 \mathrm{mmol} / \mathrm{L} \mathrm{CaCl}_{2}$ ) and incubated with fluorescein isothiocyanate-labeled annexin- $\mathrm{V}$ (Roche Diagnostics, Basel, Switzerland) and propidium iodide for 15 minutes at room temperature in the dark. Flow cytometry was performed using a FACSCanto instrument. Annexin$\mathrm{V}$-positive/propidium iodide-negative cells were considered early apoptotic, whereas annexin- $\mathrm{V}$-positive/propidium iodide-positive cells were considered late apoptotic; annexin$\mathrm{V}-$ positive cells were defined as total apoptosis.

\section{Immunohistochemistry}

Paraffin-embedded sections ( $2 \mu \mathrm{m}$ thick) of human CCA and $\mathrm{HCC}$ and liver metastasis from colorectal cancer were incubated with Antigen Retrieval for 25 minutes at $98^{\circ} \mathrm{C}$ in Citrate Buffer (pH 6.0) for FGFR1 and EDTA buffer ( $\mathrm{pH}$ 8.0) for FGFR2 (Bioptica, Milan, Italy). Sections were incubated with FGFR1 (number 9740; Cell Signaling Technology; dilution 1:200) or FGFR2 [FGFR2 antibody (number 11835; Cell Signaling Technology; dilution 1:50] for 1 hour at room temperature, MACH4 (Biocare, Pacheco, CA) for 30 minutes at room temperature, and then diaminobenzidine (Biocare) for 5 minutes at room temperature. In addition, sections were stained with hematoxylin for 1 minute. FGFR1 and FGFR2 detection was accomplished using an automatic immunohistochemical staining machine (Dako, Carpinteria, CA). ${ }^{16}$ The positive cell proportion was classified into four grades $(<1 \%$, $1 \%$ to $30 \%, 31 \%$ to $50 \%$, and $51 \%$ to $100 \%$ ). The staining intensity was graded from 0 to 3 ( 0 , no staining; 1 , weak staining; 2, moderate staining; and 3, strong staining). After summing two grades, a total staining score was obtained for one section. A section was considered positive if the total staining score was $>4$. Analysis was performed in a blinded manner by a board-certified pathologist (A.D. or L.D.T.).

\section{Real-Time Quantitative PCR}

Total RNA was extracted with the RNeasy kit (Qiagen, Düsseldorf, Germany), according to the manufacturer's instructions. RNA concentration and quality were measured using an optical NanoDrop ND1000 spectrophotometer (Thermo Fisher Scientific). Total RNA (500 ng) was transcribed with a High-Capacity cDNA Reverse Transcription Kit (Applied Biosystems, Beverly, MA). Changes in the mRNA expression level of target genes were detected using FAST SYBR-Green PCR Master Mix and the 7900HT Fast Real Time PCR System (Applied Biosystems). RNA isolated from human tissue samples was reverse transcribed using the $\mathrm{Su}$ perScript Vilo cDNA Synthesis Kit (Invitrogen, Carlsbad, 


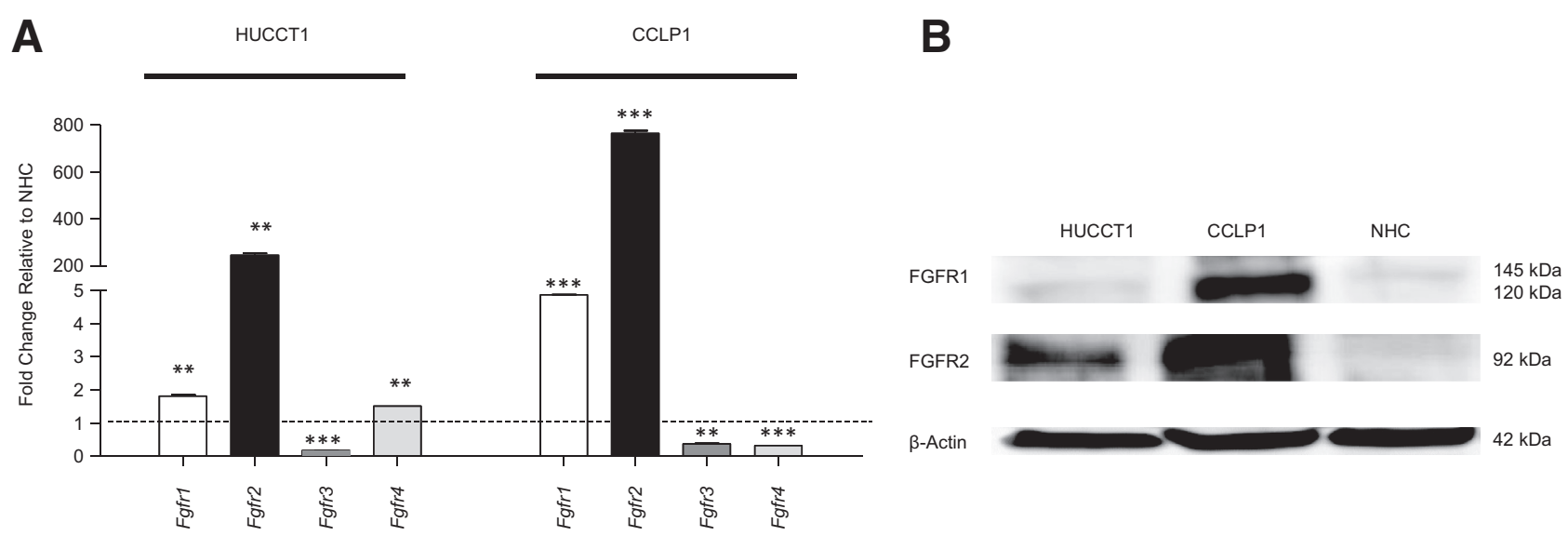

Figure 1 Expression of fibroblast growth factor receptor (FGFR) members in cholangiocarcinoma cells. A: Relative expression of transcript-encoding receptors for Fgfrs 1-4 in CCLP1 and HUCCT1 cells. Gapdh was used as an internal control. All mRNA levels are presented as fold changes normalized to 1 [mean expression of normal human cholangiocytes (NHCs) represented as dashed line in the graph]. B: Western blot analysis was used to determine total FGFR1 and FGFR2 in HUCCT1 and CCLP1 cells. Equal loading was evaluated using anti- $\beta$-actin antibody. Data are expressed as means \pm SEM (A). ${ }^{* *} P<0.01$, $* * * P<0.001$ versus NHCs ( $t$-test).

CA), according to the manufacturer's instructions. Real-time quantitative PCR was performed with the iQ SYBR Green Supermix (Bio-Rad, Milan, Italy), according to the manufacturer's instructions. The mRNA levels of glyceraldehyde-3phosphate dehydrogenase (Gapdh) were used for normalization. For the CCA cell lines, fold difference $\left(2^{-\Delta \Delta} C_{T}\right)$ was calculated using the $\Delta \mathrm{C}_{\mathrm{T}}$ of normal human cholangiocytes; for CCA tissue, surrounding tissues were used as control. All reactions were performed in triplicate. PCR was performed on cDNA with human gene-specific primer pairs for Fgfrs $1-4^{27}$ and Fgfr2-Pphln $1 .{ }^{24}$

\section{Chemoinvasion Assays}

Subconfluent CCLP1 cells were treated with vehicle or ARQ 087 at 0.3 and $1 \mu \mathrm{mol} / \mathrm{L}$ for 2 hours and then washed, trypsinized, and resuspended in serum-free medium at a concentration of $1.5 \times 10^{5}$ cells $/ \mathrm{mL}$. Chemoinvasion was measured in a modified Boyden chamber equipped with $8-\mu \mathrm{m}$ pore filters (Millipore Corp., Burlington, MA) coated with Matrigel (150 $\mu \mathrm{g} / \mathrm{mL}$; BD Biosciences, San Jose, CA), as described previously. ${ }^{28}$ After incubation (24 hours), the cells that invaded the underside of the filters were fixed, stained with Giemsa, mounted, and counted at $\times 40$ magnification. Values for invasion were expressed as the average number of invading cells per microscopic field $(\times 40)$ over five fields. Each experiment was performed in triplicate.

\section{Gene Silencing}

All siRNAs used were purchased from Dharmacon (Milan, Italy). Transfection of human CCLP1 was performed with the Amaxa nucleofection technology (Lonza, Basel, Switzerland), as previously described, with $100 \mathrm{nmol} / \mathrm{L}$ smart Pool siRNA specific for human Fgfrl or Fgfr2, in combination, or nontargeting siRNA. ${ }^{29}$

\section{Statistical Analysis}

GraphPad Prism software version 5 (GraphPad Software, San Diego, CA) was used for data analysis. Error bars represent $1 \pm$ SEM. $P$ value was calculated by $t$-test. Statistical significance and $P$ value are shown, where relevant.

\section{Results}

Different FGFRs Are Expressed in Human CCA Cell Lines

First, the expression of Fgfrs 1-4 in human iCCA cell lines was assessed. Albeit at different levels, both CCLP1 and HUCCT1 cells displayed increased Fgfrl and Fgfr2 gene and protein expression (Figure 1) compared with normal human cholangiocytes, thereby mirroring the heterogeneity in tumorigenic potential. ${ }^{22,30}$ Gene expression analysis of the HCC cell lines, PLC/PRF/5, Huh7, and HepG2, revealed minimal expression of $F g f r 2$ compared with Fgfrl (Supplemental Figure S1). This suggests that Fgfrl expression can affect HCC development. Collectively, these findings indicate that FGFR2 may have a specific role in the malignant transformation of cholangiocytes.

\section{Evaluation of the Expression of FGFRs in Human CCA Specimens}

Fgfr mRNA expression was also measured by quantitative RT-PCR using archival material of 33 iCCA patients. To further validate the in vitro data, the $F g f r 2$ gene was found to be the most consistently overexpressed gene in CCA tissues (Figure 2A and Supplemental Tables S1 and S2). Protein overexpression of the FGFR1 and FGFR2 proteins was evident in paraffin-embedded sections of iCCA $(n=19)$ (Figure 2, B-D) and tissue sections from HCC $(n=10)$ (Figure 2E), and liver metastases from colorectal cancer $(n=$ $2)$ and a hepatic adenoma $(n=1)$ were used as negative 
A
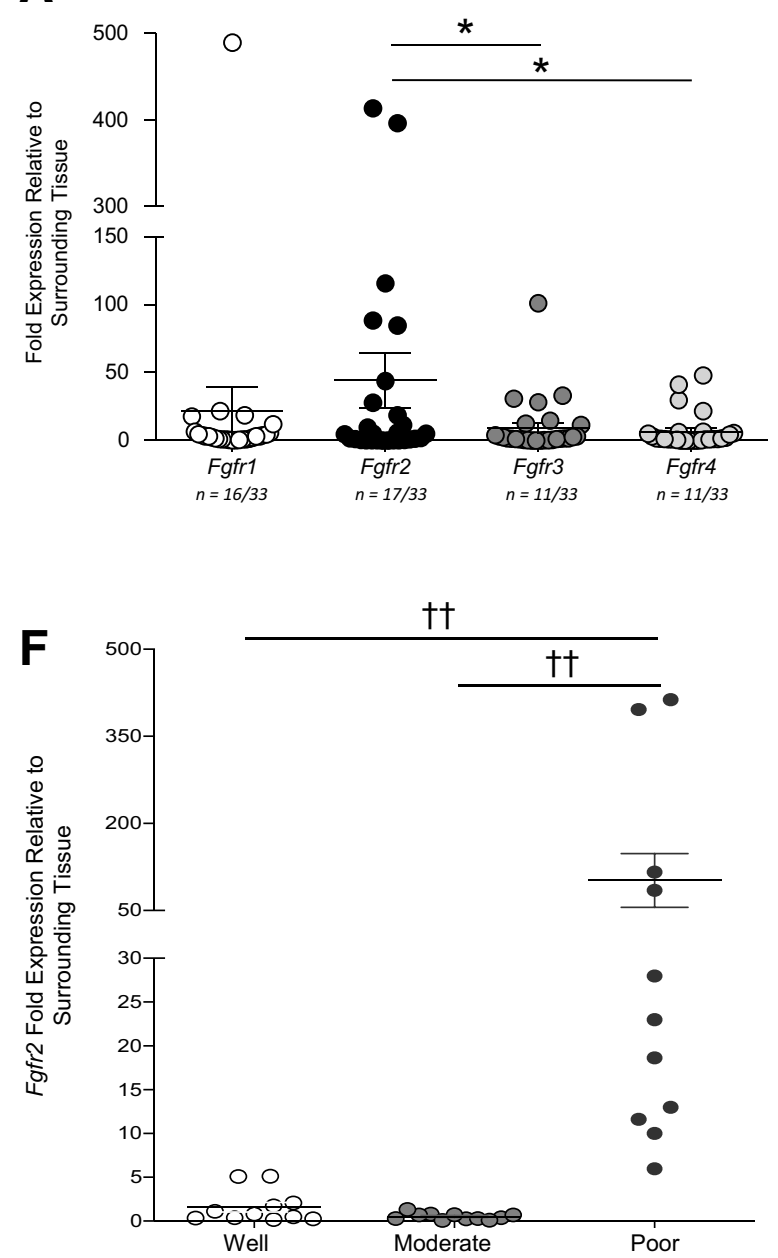

Tumor Differentiation
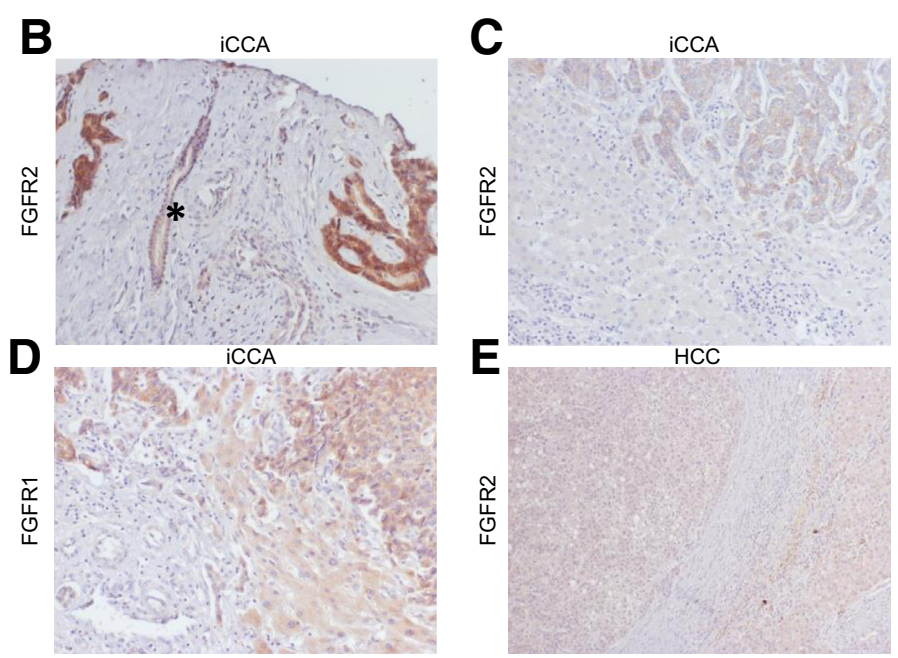

Figure 2 Presence of fibroblast growth factor receptor (FGFR) members in cholangiocarcinoma (CCA) patients. A: Relative Fgfr mRNA expression (real-time quantitative PCR) in (CA tumors compared with surrounding human liver tissue. All mRNA levels are displayed as fold changes normalized to 1 (mean expression of surrounding tissue). Data are dot plots, with lines representing means ( $P$ value versus $F g f r 2$ by one-tailed $t$-test). Frequency of positive expression is reported as fold $>2$ per Fgfr1-4 gene. B: FGFR2 immunohistochemical expression in CCA. Strong, cytoplasmic expression level of FGFR2 is observed in CCA glands embedded in a rich fibrous stroma; an entrapped bile duct (asterisk) shows negative staining (FGFR2 immunostaining). C: A moderate, cytoplasmic expression level of FGFR2 is seen in well-differentiated neoplastic glands of a CCA facing the surrounding liver parenchyma; hepatocytes and inflammatory cells are negative (FGFR2 immunostaining). D: A poorly differentiated CCA showing faint to moderate, cytoplasmic expression of FGFR1 (FGFR1 immunostaining). E: A hepatocellular carcinoma (left) and the surrounding liver parenchyma (right) are negative for FGFR2 (FGFR2 immunostaining). F: Correlation between Fgfr2 expression and tumor differentiation grade (analysis of variance test applied to compare well or moderate with poor). Data are expressed as dot plots, with lines representing means. Data are expressed as means \pm SEM ( $A$ and F). $n=33$ CCA tumors (A) and total $(\mathbf{F}) ; n=18$ human liver tissue $(\mathbf{A}) ; n=19$ (B); $n=8$ per group $(\mathbf{F}) .{ }^{*} P<0.05$ versus $F g f r 2$ (one-tailed $t$-test); ${ }^{\dagger \dagger} P<0.01$ versus poor differentiation grade (analysis of variance test). Original magnification, $\times 40$ (B-E). HCC, hepatocellular carcinoma; iCCA, intrahepatic CCA. controls. Via immunohistochemistry, FGFR2 expression could be demonstrated in $65 \%$ of all iCCAs, whereas FGFR1 was revealed in $30 \%$ of all CCAs (Supplemental Table S1). Biochemically, FGFR2 immunoreactivity was observed in CCA both in the cytosol and plasma membrane (Figure 2, B and C). HCC showed no immunoreactivity with the antibody to FGFR2 (Figure 2E) and low immunoreactivity toward FGFR1, consistent with a previous study. ${ }^{31}$ Normal liver tissue displayed no immunoreactivity for either FGFR1 or FGFR2. Analysis of $F g f r 2$ gene expression and clinicopathologic data from CCA patients revealed a good correlation between strong $\mathrm{Fgfr} 2$ expression and reduction of tumor differentiation (Figure $2 \mathrm{~F})\left(n=26\right.$, grade $\mathrm{G}_{1}>\mathrm{G}_{2}>\mathrm{G}_{3}$; the correlation analysis was performed with the 26 cases that had a clear tumor grade of 33 listed) (Supplemental Table S2), as shown by immunohistochemical staining (Figure 2, B and C). Although our immunohistochemical cohort was mainly composed of $\mathrm{G}_{3} \mathrm{CCA}$ tissues, it could not confirm the gene expression correlation data. Nonetheless, these results suggest that FGFR2 might be an important player in CCA tumor progression.

\section{Effect of DZB on CCA Cell Viability}

To verify the inhibitory effect of DZB on cancer cell growth, CCLP1 and HUCCT1 cells were treated with increasing concentrations of DZB $(0.1,0.3,1,3$, and $10 \mu \mathrm{mol} / \mathrm{L})$ for 2 , 24, and 72 hours (Figure 3 and Supplemental Table S3). An inhibitory drug effect was recognized that was dose dependent on CCA cell viability, suggesting a potential pharmacologic effect in vitro. In fact, pharmacologic effectiveness was found to vary based on the cell line used. We speculated that the different drug responses of CCA cell lines might be due to FGFR's spectrum of expression (Figure 1A). In addition, to further validate the biological significance of FGFR signaling inhibition in CCA cells, three additional commercially available anti-FGFR inhibitors [namely, TG10052 hydrochloride (0.001 to $0.1 \mu \mathrm{mol} / \mathrm{L}$ ), ENMD-2076 

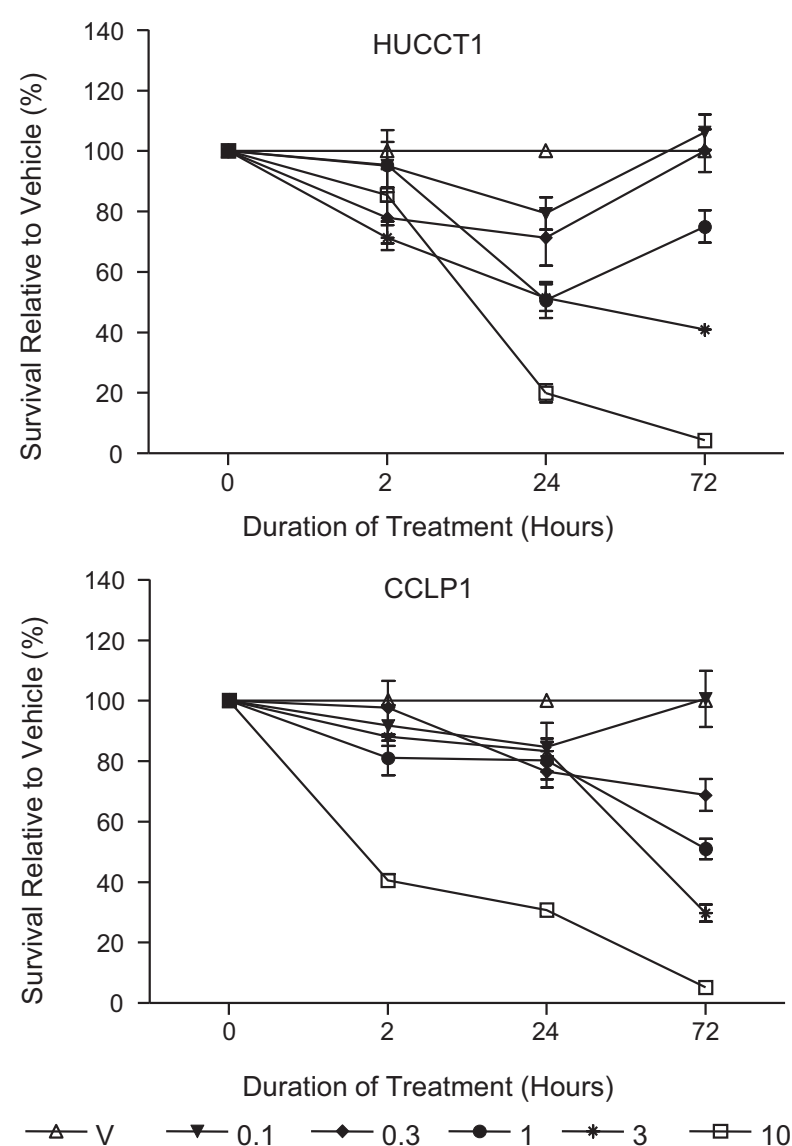

Figure 3 Effect of derazantinib (DZB) on cholangiocarcinoma (CCA) viability. Relative cell viability of CCA cell lines at different concentrations of DZB after 2, 24, and 72 hours of treatment. Cell survival was analyzed using MTT assay. All levels are displayed as percentage of vehicle (V) sample. Data are expressed as means \pm SEM. $n=5$.

(0.001 to $1 \mu \mathrm{mol} / \mathrm{L})$, and ENMD-2076 tartrate $(0.001 \mu \mathrm{mol} / \mathrm{L}$ to $0.1 \mathrm{mmol} / \mathrm{L}$ )] were tested. ${ }^{32-35}$ In both CCA cell lines (CCLP1 and HUCCT1), the latter compounds revealed inhibitory results similar to DZB (Supplemental Figure S2).

\section{DZB Inhibitory Effect on the FGFR Pathway in CCA Cells}

Using the agonist FGF7, inhibiting FGFR2 phosphorylation by DZB treatment after receptor activation could progressively reduce phosphorylation in a concentration-dependent manner (Figure 4A and Supplemental Figure S3). DZB inhibited the phosphorylation of FGFR1 to FGFR2 in all CCA cell lines in a dose-dependent manner, indicating a possible inhibitory pharmacologic impact on FGFR phosphorylation/activation.

Although the anti-phospho-FGFR antibody does not discriminate among different phosphorylated FGFRs, because the cell lines express high levels of both FGFR1 and FGFR2, this may support the notion that the reduction of the phospho-FGFR signal was mainly due to the inhibition of phospho-FGFRs 1 and 2 (Figure 4A and Supplemental Figure S3). Only transfection experiments could, therefore, clearly reveal which FGFR member would be relevant for CCA pathogenesis.

The signal transduction pathways activated downstream of FGFR in the CCA cell lines were examined. By inhibiting FGFR phosphorylation, DZB caused the dephosphorylation of further downstream components, such as ERK1/2, AKT, and P38 (Figure 4B). Furthermore, down-regulation of liver cancer stem-like genes (Supplemental Figure S4) and molecules involved in angiogenesis (FGF2, angiopoietin-1 proteins, and Vegfgene) (Figure 4B and Supplemental Figure S4) was observed. This result suggested that DZB has a downstream effect that leads to tumor disruption. Collectively, this result positively correlates with the in vitro antiproliferative activity of DZB in CCA cell lines.

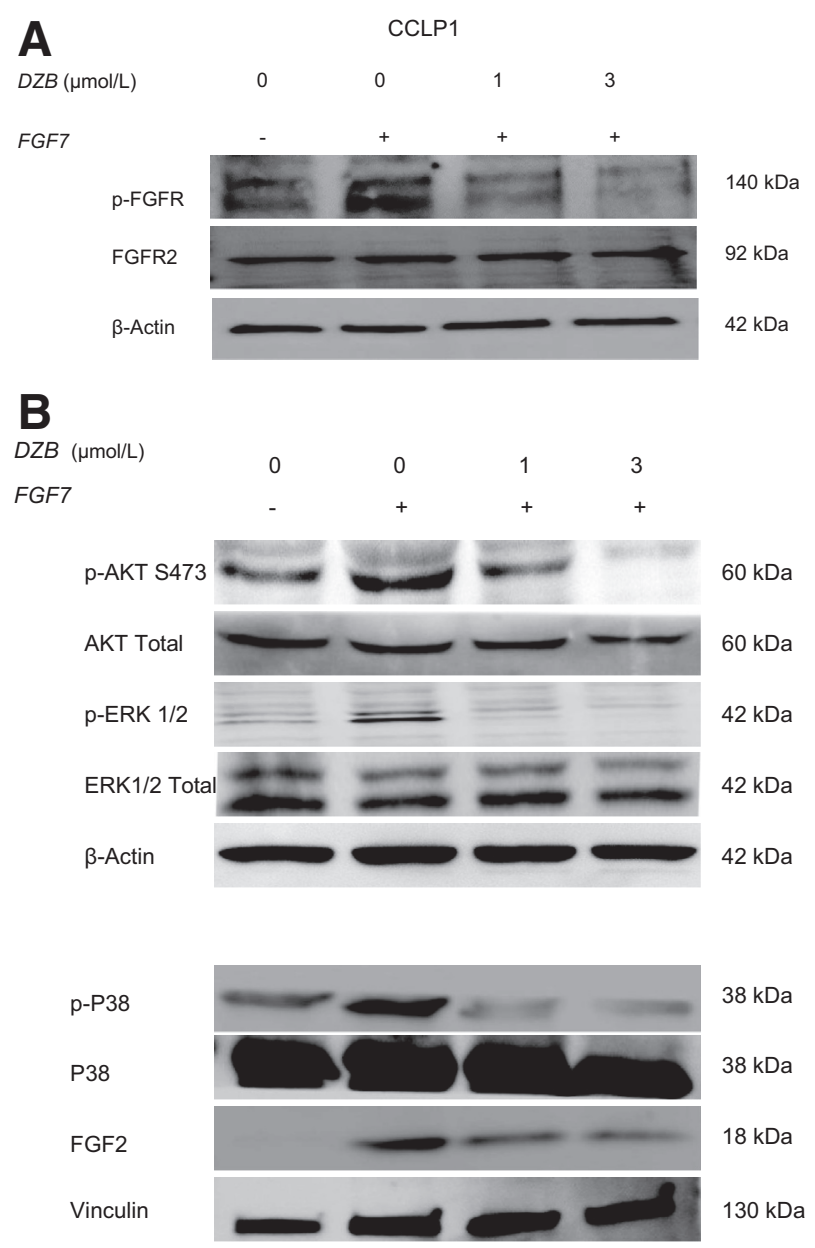

Figure 4 Derazantinib (DZB) inhibition of the fibroblast growth factor receptor (FGFR) pathway in cholangiocarcinoma cells. A: After treatment with increasing concentrations of DZB $(0.1,0.3,1,3$, and $10 \mu \mathrm{mol} / \mathrm{L})$, CCLP1 cells were stimulated with FGF7, an FGFR receptor agonist. In CCLP1 cells, FGFR activation by FGF7 $(0+)$ is shown to result in major phosphorylation relative to the control (0-) in the absence of DZB treatment. B: DZB inhibits ligand-dependent phosphorylation and activation of the downstream signaling pathways of FGFR. Subconfluent CCLP1 cells were treated with indicated concentrations of DZB for 2 hours, followed by stimulation with FGF7 for 15 minutes. Lysates were prepared, and phosphorylated ( $p-)$ and total FGFR2, AKT, extracellular signal-regulated kinase (ERK) $1 / 2$, P38, and FGF2 were detected by immunoblot analysis. $\beta$-Actin and vinculin were used as loading controls. 
A

Vehicle

DZB

$0.3 \mu \mathrm{mol} / \mathrm{L}$
DZB

$1 \mu \mathrm{mol} / \mathrm{L}$

B
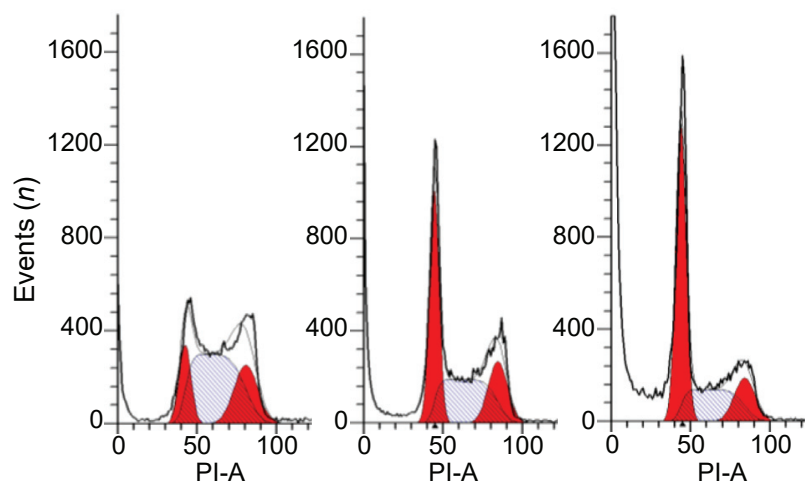

C

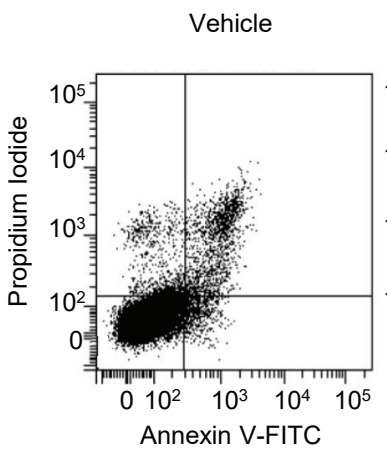

DZB $0.3 \mu \mathrm{mol} / \mathrm{L}$

DZB $1 \mu \mathrm{mol} / \mathrm{L}$
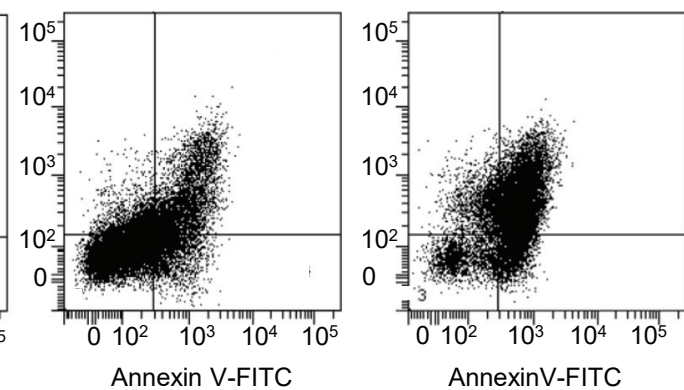

E

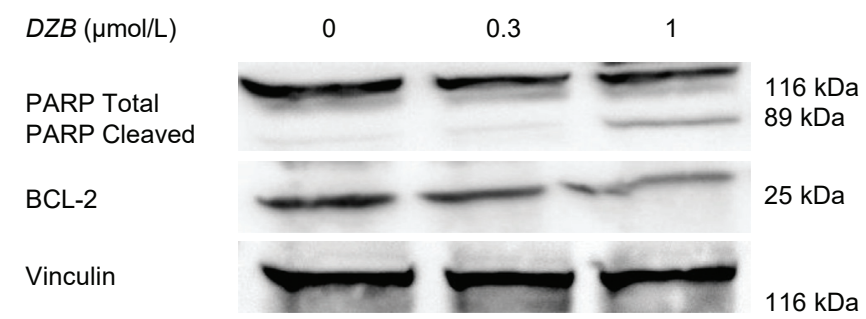

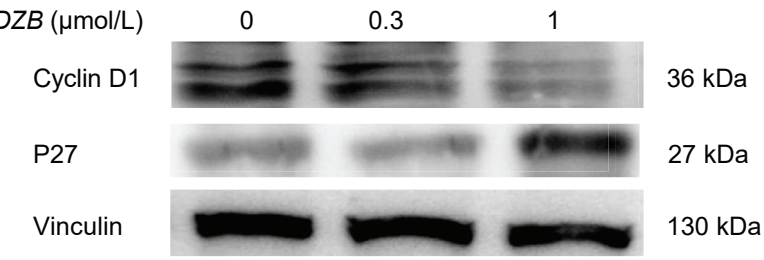

D

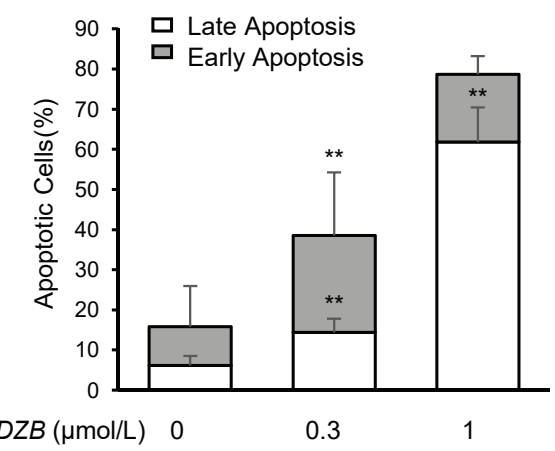

F

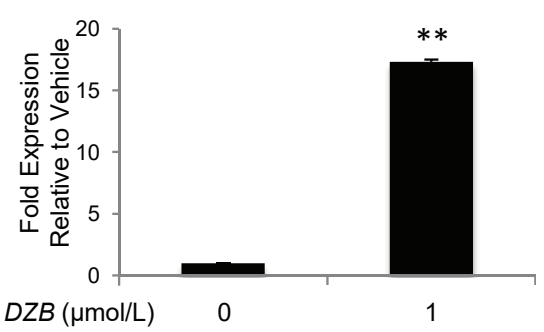

Figure 5 Derazantinib (DZB) induces $\mathrm{G}_{1}$ cell cycle arrest and apoptosis in cholangiocarcinoma cells. A: CCLP1 cells were treated with 0.3 or $1 \mu$ mol/L of DZB or vehicle for 72 hours. Cell cycle profiles were measured by flow cytometric analyses. Gating was performed to exclude cellular debris. Representative dot plots are shown. CCLP1 cells were treated with 0.3 or $1 \mu \mathrm{mol} / \mathrm{L}$ of ARQ 087 or vehicle for 72 hours. B: Western blot analysis was performed for cyclin D1 and P27. Vinculin was used as the loading control. C: CCLP1 cells were treated with 0.3 or $1 \mu \mathrm{mol} / \mathrm{L}$ of DZB or vehicle for 72 hours and used in an annexin V/propidium iodide assay to determine the percentage of cells in early or late apoptosis. Representative dot plots are shown. D: Graph bar summarizes percentage of cells alive and in early and late apoptotic phases. E: CCLP1 cells were treated with 0.3 or $1 \mu \mathrm{mol} / \mathrm{L}$ of DZB or vehicle for 72 hours. Western blot analysis was performed for cleaved poly (ADPribose) polymerase (PARP) and BCL-2. Vinculin was used as the loading control. F: Casp1 gene expression after a 72-hour treatment with ARQ 087, $1 \mu$ mol/L, or vehicle. Gapdh was used as the internal control. Levels of mRNA are displayed as $\Delta C_{\mathrm{T}}$. $P$ value versus vehicle sample by $t$-test. Data are expressed as means $\pm \mathrm{SEM}$ (D and $\mathbf{F}) . n=5(\mathbf{D}) ; n=3(\mathbf{F}) .{ }^{*} P<0.01$ versus relative vehicle ( $t$-test). FITC, fluorescein isothiocyanate; PI-A, propidium iodide-annexin V.

\section{DZB Induced Cell Cycle Arrest and Apoptosis}

To explain the decrease in cell viability, the effects of DZB were evaluated on cell cycle and apoptotic responses. Treatment with DZB led to cell accumulation in the $\mathrm{G}_{0} / \mathrm{G}_{1}$ phase of the cell cycle in a dose-dependent manner. Concomitantly, the percentage of cells in the $\mathrm{S}$ phase was found to be reduced
(Figure 5A and Table 1). These data were corroborated by the down-regulation of cyclin D1, together with the overexpression of P27 tumor suppressor (Figure 5B). To evaluate whether, besides cell cycle arrest, the reduction of cell number in the culture was due to an increase in apoptosis, CCLP1 cells were treated with 0.3 and $1 \mu \mathrm{mol} / \mathrm{L}$ of DZB for 72 hours. Furthermore, cleaved poly (ADP-ribose) polymerase, BCL2, 
Table 1 Percentage of Cells in $\mathrm{G}_{0} / \mathrm{G}_{1}, \mathrm{~S}$, and $\mathrm{G}_{2}$ Phases

\begin{tabular}{lllc}
\hline Phase & Vehicle & DZB $(0.3 \mu \mathrm{mol} / \mathrm{L})$ & DZB $(1 \mu \mathrm{mol} / \mathrm{L})$ \\
\hline $\mathrm{G}_{0} / \mathrm{G}_{1}$ & $14.9 \pm 1.3$ & $35.0 \pm 6.6^{*}$ & $63.2 \pm 5.4^{* *}$ \\
$\mathrm{~S}$ & $62.4 \pm 1.8$ & $42.3 \pm 4.8^{*}$ & $24 \pm 2.9^{* *}$ \\
$\mathrm{G}_{2} / \mathrm{M}$ & $22.7 \pm 0.5$ & $22.7 \pm 1.9$ & $12.8 \pm 3.5^{*}$ \\
\hline
\end{tabular}

Data are expressed as means \pm SEM. $n=5$.

${ }^{*} P \leq 0.05,{ }^{* *} P \leq 0.01$ versus relative vehicle ( $t$-test).

DZB, derazantinib.

and gene expression of caspase1 (Caspl) were assessed by immunoblotting analysis. Notably, a 72-hour treatment with the $0.3 \mu \mathrm{mol} / \mathrm{L}$ dose could induce marked early and late apoptosis. To add, the latter was found to increase further with a higher dose of DZB $(1 \mu \mathrm{mol} / \mathrm{L})$, where $<10 \%$ of cells were still alive (Figure 5, C and D, and Supplemental Table S4). An apoptotic response was observed in CCLP1 cells after treatment with DZB by an increase in cleaved poly (ADP-ribose) polymerase protein and Caspl gene and the down-regulation of BCL2 (Figure 5, E and F). Overall, these data indicate a substantial reduction in CCA survival after DZB treatment.

\section{DZB Inhibits the Invasive Capacity of CCA Cells in Vitro}

To support the experimental results mentioned above, the negative regulation of DZB on the invasiveness of CCA cells was verified using the Matrigel invasion assay. Figure 6A shows that the invasion of CCA cells through the Matrigel decreased with the 2-hour treated cells (either 0.3 or $1 \mu \mathrm{mol} /$ L) compared with the vehicle controls. Through a quantitative analysis, the $1 \mu \mathrm{mol} / \mathrm{L}$ dose was demonstrated to be more effective at decreasing the invasiveness of these cells compared with $0.3 \mu \mathrm{mol} / \mathrm{L}$. Tumor cell invasion decreased $>30 \%$ in cells treated with $0.3 \mu \mathrm{mol} / \mathrm{L}$ and $>90 \%$ in cells treated with $1 \mu \mathrm{mol} / \mathrm{L}$ (Figure $6, \mathrm{~A}$ and B) regardless of cell viability (Supplemental Figure S5). A similar inhibitory effect was observed after treatment with the commercially available anti-FGFR inhibitors, TG10052 hydrochloride, ENMD-2076, and ENMD-2076 tartrate $^{32-35}$ (Supplemental Figure S2). Under this premise, the alterations in the expression of epithelial-mesenchymal-associated genes were further analyzed in the presence or absence of DZB treatment. DZB caused a reduction of mesenchymal markers [such as vimentin (Vim)] and a concomitant enhanced expression of the epithelial marker, E-cadherin $(C d h l)$. For $\beta$ catenin $(C t n n b 1)$, only a minimal variation in expression was observed (Figure 6C). Altogether, our results indicate that DZB significantly diminished the invasive capability of CCA.

\section{DZB Specificity in CCA Cells}

To more rigorously examine the role of single components of the FGFR family in CCA aggressiveness, the effects elicited by loss of single FGFR members were compared. To mimic the effects of receptor selective inhibition, CCLP1 cells were treated with a pool of specific Fgfrl- or Fgfr2-targeting
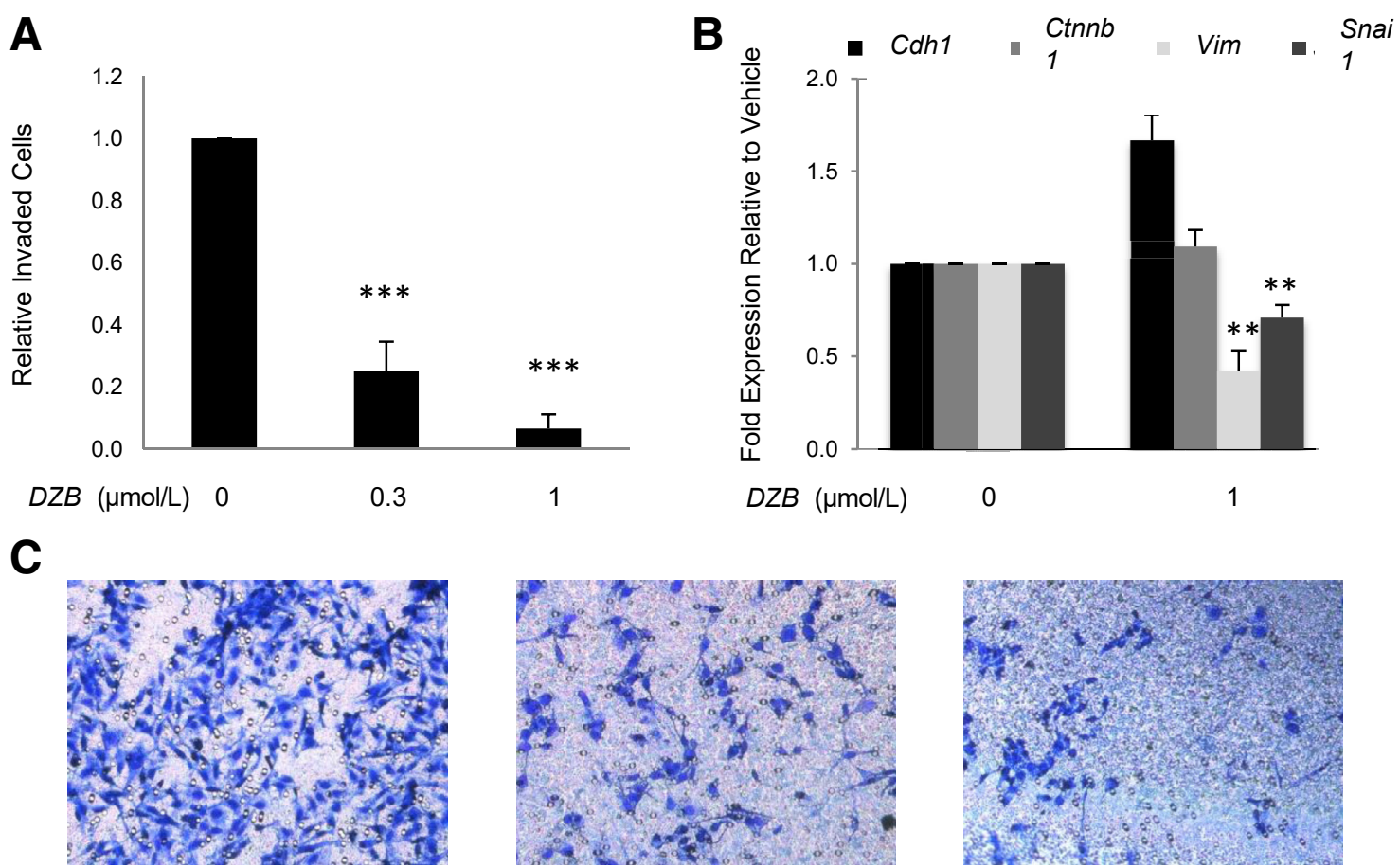

Figure 6 Reduction of the invasive capacity of cholangiocarcinoma cells by derazantinib (DZB). A: Cultured CCLP1 cells were pretreated with vehicle or the indicated concentrations of DZB for 2 hours. Thus, cells were detached from the culture dish, and invasiveness was measured in modified Boyden chambers in the absence or presence (upper chambers) of 0.3 or $1 \mu \mathrm{mol} / \mathrm{L}$ of DZB for 18 hours. Thereafter, cells were counted and normalized to invaded vehicle. B: RT-PCR analysis was performed for the epithelial-mesenchymal genes, Cdh1, Ctnnb1, Vim, and Snai1. All mRNA levels are displayed as fold changes normalized to 1 (mean expression of vehicle sample). C: Representative images of invaded CCLP1 cells in the presence or absence of DZB. Data are expressed as means \pm SEM (A and $\mathbf{B}) . n=5(\mathbf{A}) ; n=3(\mathbf{B}) .{ }^{* *} P<0.01,{ }^{* *} P<0.001$ versus vehicle sample ( $t$-test). Original magnification, $\times 20$ (C). 
A

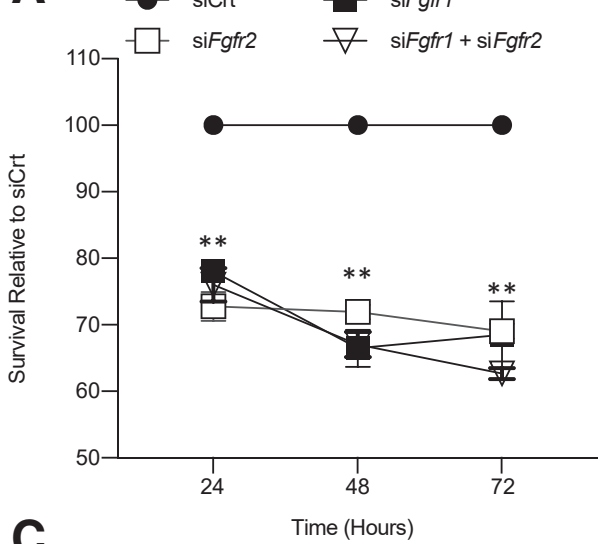

B

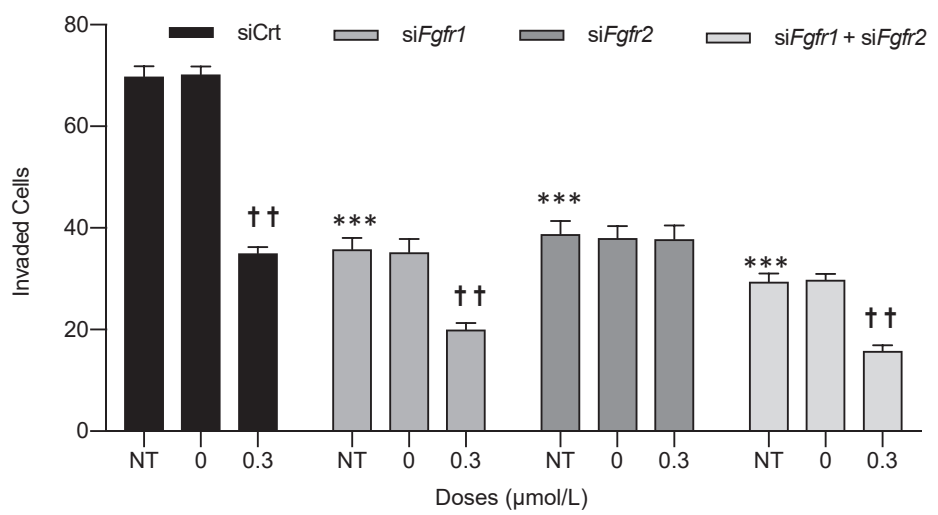

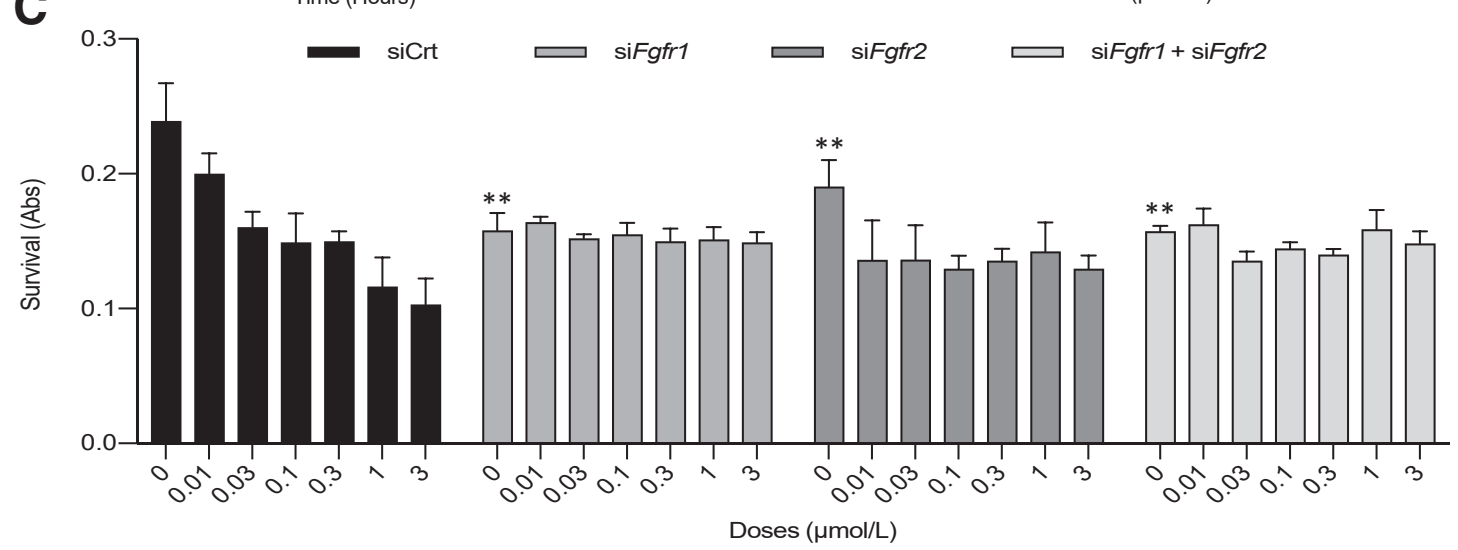

D

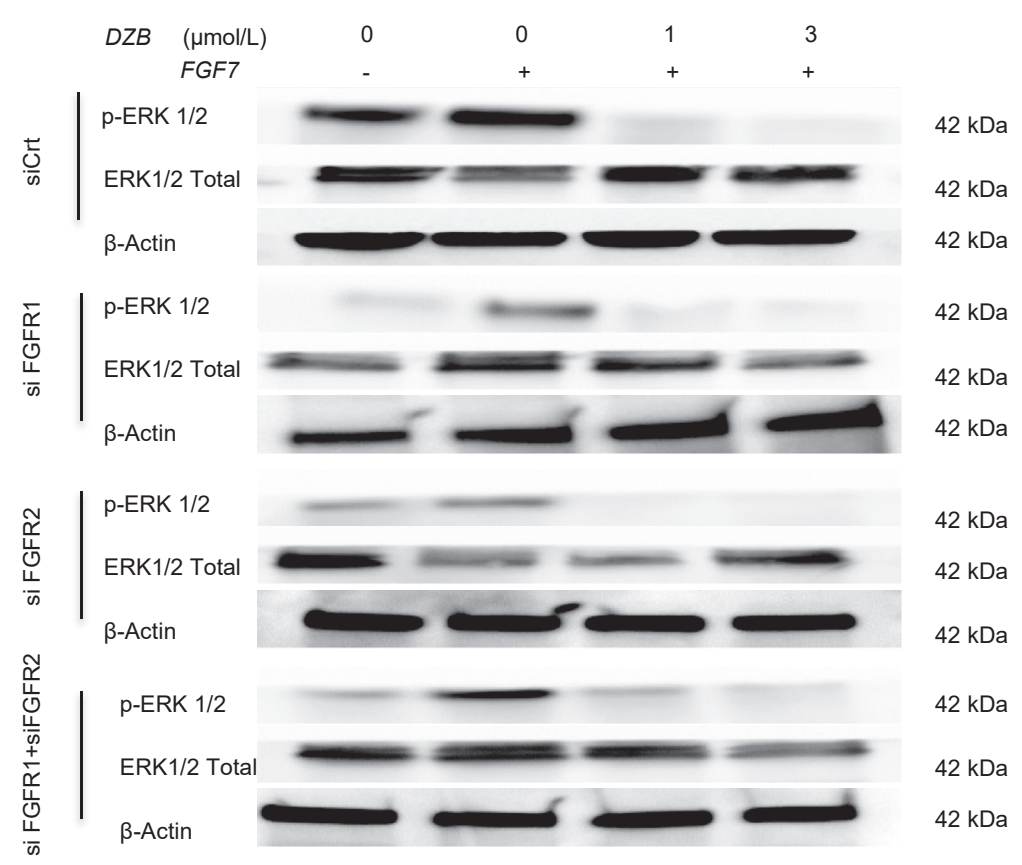

Figure 7 Effect of fibroblast growth factor receptors' (FGFRs') 1 and 2 silencing on cholangiocarcinoma cells. A: Rate of proliferation of FGFR-silenced cells (siFgfr1, siFgfr2, and siFgfr1 + siFgfr2) relative to control (siCrt), as measured by the crystal violet assay. This test was performed 48 and 72 hours after silencing. Results were normalized to that of siCrt. B: Cultured silenced CCLP1 cells were either not pretreated or pretreated with vehicle or the indicated concentrations of derazantinib (DZB) for 2 hours. Thus, cells were detached from the culture dish, and invasiveness was measured in modified Boyden chambers in the absence or presence (upper chambers) of $0.3 \mu \mathrm{mol} / \mathrm{L}$ DZB for 18 hours. Nontreated cells (NTs) are shown. Cells per field (10 fields) are represented in a graph format. C: Fgfr-silenced CCLP1 cells show sensitivity to DZB compared with siCrt. MTT test was performed after 24 hours of ARQ 087 treatment. Results were displayed as absorbance (Abs) readings. D: Immunoblot analysis was used to detect the levels of phosphorylated extracellular signalregulated kinase ( $p$-ERK) $1 / 2$ proteins after siRNA Fgfr silencing alone and in combination with ARQ treatment for 24 hours. Data are expressed as means \pm SEM $(\mathbf{A}-\mathbf{C}) . n=3(\mathbf{A}$ and $\mathbf{C}) ; n=5(\mathbf{B}) .{ }^{*} P<0.01,{ }^{* * *} P<0.001$ versus NT siCrt sample $\left(t\right.$-test); ${ }^{\dagger \dagger} P \leq 0.01$ versus vehicle sample $(t$-test). 


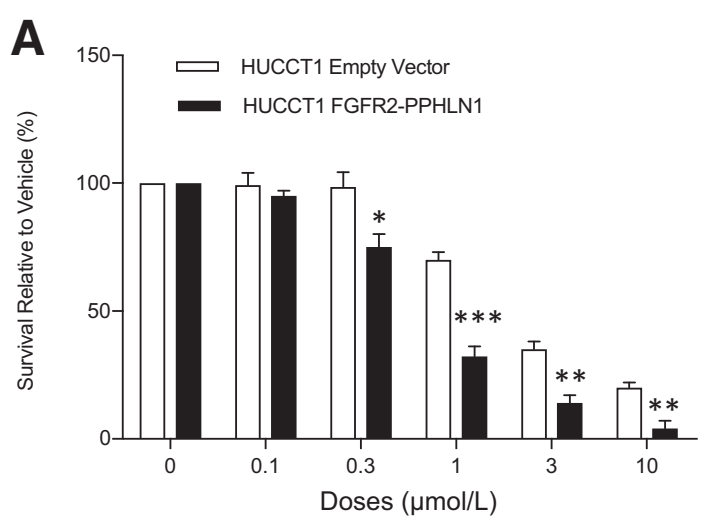

B
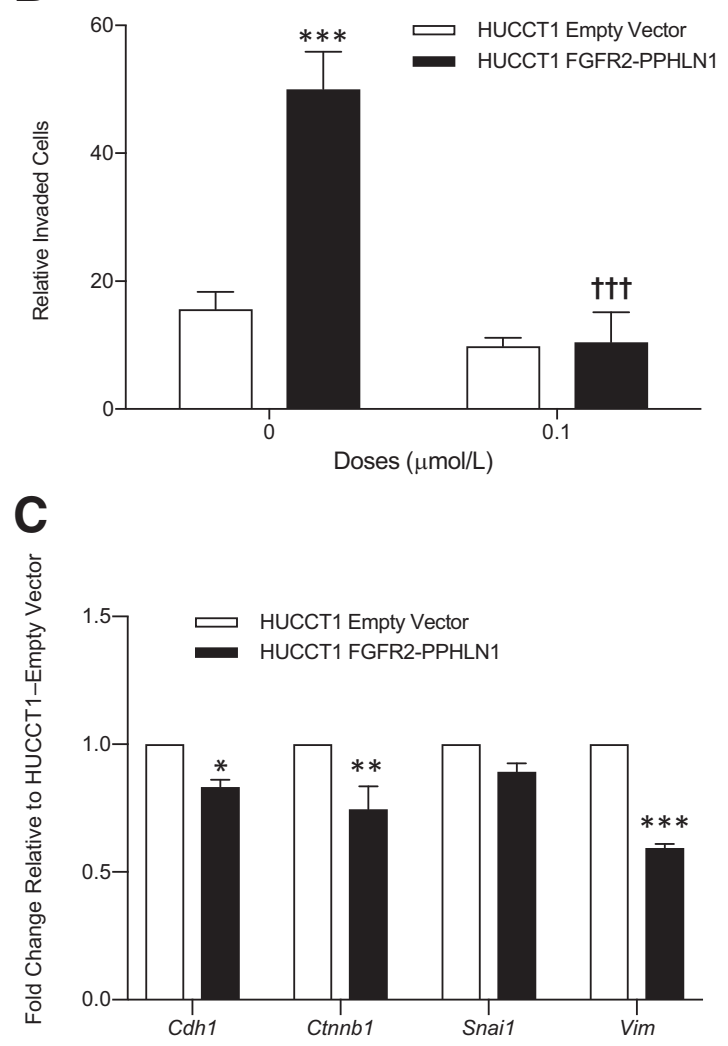

Figure 8 Fibroblast growth factor receptor (FGFR) 2 fusions represent a potential therapeutic target. A: The HUCCT1 cell line transfected to overexpress FGFR2-periphilin 1 (PPHLN1) has increased sensitivity to derazantinib (DZB) compared with its parental cell line transfected with the empty vector. MTT test was performed after a 24-hour DZB treatment. Results were normalized to vehicle (dimethyl sulfoxide). B: DZB $(0.1 \mu \mathrm{mol}$ ) $\mathrm{L})$ reduces cell migration only in the HUCCT1 cell line expressing FGFR2PPHLN1. Cultured FGFR2-PPHNL1 cells were pretreated with vehicle or the indicated concentrations of DZB for 2 hours. Thus, cells were detached from the culture dish, and invasiveness was measured in modified Boyden chambers in the absence or presence (upper chambers) of $0.1 \mu \mathrm{mol} / \mathrm{L}$ DZB for 18 hours. Invaded cells per field (10 fields) are represented in graph. C: Relative expression of transcript-encoding epithelial-mesenchymal genes in HUCCT1 FGFR2-PPHNL1 and relative empty vector cells after DZB treatment. Gapdh was used as the internal control. All mRNA levels are presented as fold changes normalized to 1 (mean expression of empty vector). Data are expressed as means $\pm \mathrm{SEM}(\mathbf{A}-\mathbf{C}) . n=3(\mathbf{A}) ; n=5$ (B). ${ }^{*} P<0.05$, ${ }^{* *} P<0.01$, and ${ }^{* * *} P<0.001$ versus empty vector sample ( $t$-test); ${ }^{\dagger \dagger \dagger} P<$ 0.001 versus vehicle of the HUCCT1 FGFR2-PPHLN1 cells ( $t$-test).
siRNAs (siFGFR1, siFGFr2) that completely abolished receptor expression (Supplemental Figure S6). Single and combination siFgfrl and siFgfr2 silencing significantly reduced cell proliferation, invasion capability (Figure 7, A-C), and ERK1/2 phosphorylation (Figure 7D). The notable decrease in ERK1/2 activation in the ERK1/2 signal transduction pathway indicates that it is a key downstream signaling protein associated with FGFRs 1 and 2 in human CCA. These results also indicate that FGFR1 and FGFR2 are both critical drivers of CCA malignancy.

To verify the possible synergism of DZB treatment on FGFR-depleted cells, efficacy of drug treatment combined with siRNA on CCA cells was considered in vitro. As expected, DZB treatment did not significantly impact survival of FGFR-silenced CCA cells (Figure 7C); however, DZB mainly acted on FGFR2 receptor, as indicated by the effect of a $0.3 \mu \mathrm{mol} / \mathrm{L}$ dose on invasion capability (Figure $7 \mathrm{~B}$ ). Our results highlighted FGFR2 as an excellent target for chemotherapy with DZB, and this might add to the literature, especially because this molecule is currently under clinical investigation (NCT03230318). Appropriately combining the anti-FGFR inhibitor with an siFGFR1siFGFR2 tool might be a future strategy for CCA treatment.

\section{DZB Growth Inhibition in FGFR Dysregulated CCA Cells}

Previous studies of several targeted therapies against solid tumors strongly argue that genetic alterations of target molecules (eg, gene amplification, mutations, or fusion gene) are important hallmarks of pathway addiction and drug response. ${ }^{36}$ In this respect, FGFR2 fusions represent the most recurrent targetable alteration in CCA patients. ${ }^{13}$ To add, a new FGFR2-PPHLN1 fusion has recently been described in CCA. ${ }^{24}$ Hence, the biological activity of DZB was evaluated in a CCA cell line stably overexpressing the FGFR2-PPHLN1 fusion protein. ${ }^{24}$ Notably, FGFR2-PPHLN1 cells showed enhanced sensitivity to DZB compared with their parental cell line transfected with the empty vector (Figure 8, A and B, and Supplemental Figure S7). In particular, significant inhibition of the migratory capability (Figure 8B) and expression of epithelial-mesenchymal genes (Figure 8C) were observed only in HUCCT1 cells expressing the fusion protein. The above findings support the transforming and oncogenic potential of FGFR2-PPHLN1 fusion protein and the possible efficacy of DZB in the clinical management of CCA patients harboring FGFR2 rearrangements.

\section{Discussion}

Our findings demonstrate the in vitro preclinical activity of DZB in human iCCA. As previously reported, ${ }^{14-17}$ DZB inhibited FGFR kinases by an ATP competitive mechanism and delayed FGFR activation by inhibiting its autophosphorylation and the phosphorylated active kinase. By using multiple cell systems' ectopically expressing FGFR receptors, DZB was recently found to inhibit cell proliferation 
as a functional consequence of FGFR phosphorylation inhibition in a preferential manner, in the order, FGFR2 $\gg$ FGFR1/FGFR3 $\gg$ FGFR4.

Our study showed that treating FGFR-overexpressing CCA cells with DZB affected their signal transduction pathways, thereby impacting tumor cell proliferation, death, and invasiveness. DZB was tested in a phase $1 / 2$ clinical trial (NCT03230318) and demonstrated meaningful clinical benefits for patients with iCCA harboring tumors with a dysregulated FGFR pathway, specifically FGFR2 fusions.

Our study confirmed that the genetic and protein overexpression levels of FGFRs 1 to 4 are important in iCCA. ${ }^{27}$ Among FGF receptors, CCA cells expressed high levels of FGFR2, as shown by the immunohistochemical and gene expression data. In contrast, both HCC cells and nonmalignant cholangiocytes (normal human cholangiocyte cells) expressed low levels of FGFR, suggesting that FGFR may have a role in the malignant transformation of tumor cholangiocytes and implying that FGFRs might represent potential CCA-specific markers.

In vitro studies on malignant CCA cell lines (CCLP1 and HUCCT1) overexpressing various FGFR subtypes revealed the antiproliferative response that occurs toward DZB. DZB dose dependently inhibited proliferation and cell line specificity. Furthermore, its impact on CCA proliferation was found to be a result of the deactivation of ERK1/2 and AKT signaling pathways and activation of apoptotic and cell growth arrest signaling. Notably, invasion was reduced by a 2-hour pretreatment with DZB, as shown by the number of invaded cells through Matrigel devices; and this result was also corroborated by the down-regulation of key epithelialmesenchymal genes.

In summary, we have presented a mechanistic description of a novel kinase inhibitor that displays potent in vitro activity in FGFR-driven models, thereby confirming its good drug-like properties. To add, we demonstrated the activity of DZB on CCA cell lines expressing Fgfr mRNA and protein and showed that DZB might be active in tumors expressing FGFR and is independent of FGFR fusion. DZB is currently in clinical trials for CCA. Indeed, data from a phase 1 clinical trial appears to align with the data acquired herein, as tumor response was observed in CCA with amplification, and not only fusions. ${ }^{17}$ DZB can be active in tumors that express both FGFR1 and FGFR2 (and not limited to FGFR2) based on the CCLP1 data. Currently, there are promising data on the antitumor activity of FGFR2 inhibitory compounds, but these might be limited to CCA with FGFR2 fusions (ie, not amplifications). ${ }^{37}$ Thus, identifying novel compounds with a broader spectrum of activity could be interesting.

Our future plans include testing the inhibitory effects of DZB on xenografts produced from cultured CCA cell lines injected into immunosuppressed mice. This will be performed to determine the effects of FGFR inhibition on human CCA formation and growth in vivo.

\section{Acknowledgments}

We thank Dr. Snorri S. Thorgeirsson, Valentina Factor, and Elizabeth A. Conner (Center for Cancer Research, National Cancer Institute, NIH, Bethesda, MD) for providing the hepatocarcinoma cell lines (PLC/PRF/5, Huh7, and HepG2); Dr. Anthony J. Demetris (University of Pittsburgh, Pittsburgh, PA) for cholangiocarcinoma cell lines (HUCCT1 and CCLP1); Dr. Jesus M. Banales for the human nonmalignant cholangiocyte cell line; and Prof. Vincenzo Mazzaferro (IRCCS Foundation National Cancer Institute, Milan, Italy) for the stable HUCCT1 cell line overexpressing fibroblast growth factor receptor 2-PPHLN1 fusion protein.

C.R. and P.I. designed the study and wrote the manuscript; C.R., K.F., M.P., P.B., M.C., E.F., N.N., A.G., T.H., A.D., L.D.T., M.R., F.M., S.G., E.R., C.P.-N., J.M.B., P.O., A.G., A.E., G.A., M.D.B., S.B., V.M., and F.M. provided materials, performed the experiments, collected the data, and analyzed the results; C.R., G.A., and P.I. supervised the project and critically revised the manuscript; all authors have read and approved the final manuscript.

\section{Supplemental Data}

Supplemental material for this article can be found at http://doi.org/10.1016/j.ajpath.2019.06.007.

\section{References}

1. Kumar M, Zhao X, Wang XW: Molecular carcinogenesis of hepatocellular carcinoma and intrahepatic cholangiocarcinoma: one step closer to personalized medicine? Cell Biosci 2011, 1:5

2. Leyva-Illades D, McMillin M, Quinn M, Demorrow S: Cholangiocarcinoma pathogenesis: role of the tumor microenvironment. Transl Gastrointest Cancer 2012, 1:71-80

3. Shaib YH, El-Serag HB, Davila JA, Morgan R, McGlynn KA: Risk factors of intrahepatic cholangiocarcinoma in the United States: a case-control study. Gastroenterology 2005, 128:620-626

4. Zabron A, Edwards RJ, Khan SA: The challenge of cholangiocarcinoma: dissecting the molecular mechanisms of an insidious cancer. Dis Model Mech 2013, 6:281-292

5. Aljiffry M, Walsh MJ, Molinari M: Advances in diagnosis, treatment and palliation of cholangiocarcinoma: 1990-2009. World J Gastroenterol 2009, 15:4240-4262

6. Glimelius B, Hoffman K, Sjoden PO, Jacobsson G, Sellstrom H, Enander LK, Linne T, Svensson C: Chemotherapy improves survival and quality of life in advanced pancreatic and biliary cancer. Ann Oncol 1996, 7:593-600

7. Hubbard SR, Till JH: Protein tyrosine kinase structure and function. Annu Rev Biochem 2000, 69:373-398

8. Heldin $\mathrm{CH}$ : Dimerization of cell surface receptors in signal transduction. Cell 1995, 80:213-223

9. Pawson T, Nash P: Protein-protein interactions define specificity in signal transduction. Genes Dev 2000, 14:1027-1047

10. Turner N, Grose R: Fibroblast growth factor signalling: from development to cancer. Nat Rev Cancer 2010, 10:116-129

11. Beenken A, Mohammadi M: The FGF family: biology, pathophysiology and therapy. Nat Rev Drug Discov 2009, 8:235-253 
12. Schlessinger J: Cell signaling by receptor tyrosine kinases. Cell 2000, 103:211-225

13. Banales JM, Cardinale V, Carpino G, Marzioni M, Andersen JB, Invernizzi P, Lind GE, Folseraas T, Forbes SJ, Fouassier L, Geier A, Calvisi DF, Mertens JC, Trauner M, Benedetti A, Maroni L, Vaquero J, Macias RI, Raggi C, Perugorria MJ, Gaudio E, Boberg KM, Marin JJ, Alvaro D: Expert consensus document: cholangiocarcinoma: current knowledge and future perspectives consensus statement from the European Network for the Study of Cholangiocarcinoma (ENS-CCA). Nat Rev Gastroenterol Hepatol 2016, 13:261-280

14. Yu Y, Hall T, Eathiraj S, Wick MJ, Schwartz B, Abbadessa G: In-vitro and in-vivo combined effect of ARQ 092, an AKT inhibitor, with ARQ 087, a FGFR inhibitor. Anticancer Drugs 2017, 28:503-513

15. Chila R, Hall GT, Abbadessa G, Broggini M, Damia G: Multichemotherapeutic schedules containing the pan-FGFR inhibitor ARQ 087 are safe and show antitumor activity in different xenograft models. Transl Oncol 2017, 10:153-157

16. Hall TG, Yu Y, Eathiraj S, Wang Y, Savage RE, Lapierre JM, Schwartz B, Abbadessa G: Preclinical activity of ARQ 087, a novel inhibitor targeting FGFR dysregulation. PLoS One 2016, 11:e0162594

17. Papadopoulos KP, El-Rayes BF, Tolcher AW, Patnaik A, Rasco DW, Harvey RD, LoRusso PM, Sachdev JC, Abbadessa G, Savage RE, Hall T, Schwartz B, Wang Y, Kazakin J, Shaib WL: A phase 1 study of ARQ 087, an oral pan-FGFR inhibitor in patients with advanced solid tumours. Br J Cancer 2017, 117:1592-1599

18. Mazzaferro V, El-Rayes BF, Droz Dit Busset M, Cotsoglou C, Harris WP, Damjanov N, Masi G, Rimassa L, Personeni N, Braiteh F, Zagonel V, Papadopoulos KP, Hall T, Wang Y, Schwartz B, Kazakin J, Bhoori S, de Braud F, Shaib WL: Derazantinib (ARQ 087) in advanced or inoperable FGFR2 gene fusion-positive intrahepatic cholangiocarcinoma. Br J Cancer 2019, 120:165-171

19. Miyagiwa M, Ichida T, Tokiwa T, Sato J, Sasaki H: A new human cholangiocellular carcinoma cell line (HuCC-T1) producing carbohydrate antigen 19/9 in serum-free medium. In Vitro Cell Dev Biol 1989, 25:503-510

20. Han C, Wu T: Cyclooxygenase-2-derived prostaglandin E2 promotes human cholangiocarcinoma cell growth and invasion through EP1 receptor-mediated activation of the epidermal growth factor receptor and Akt. J Biol Chem 2005, 280:24053-24063

21. Shimizu Y, Demetris AJ, Gollin SM, Storto PD, Bedford HM, Altarac S, Iwatsuki S, Herberman RB, Whiteside TL: Two new human cholangiocarcinoma cell lines and their cytogenetics and responses to growth factors, hormones, cytokines or immunologic effector cells. Int J Cancer 1992, 52:252-260

22. Banales JM, Saez E, Uriz M, Sarvide S, Urribarri AD, Splinter P, Tietz Bogert PS, Bujanda L, Prieto J, Medina JF, LaRusso NF: Upregulation of microRNA 506 leads to decreased $\mathrm{Cl}-/ \mathrm{HCO} 3-$ anion exchanger 2 expression in biliary epithelium of patients with primary biliary cirrhosis. Hepatology 2012, 56:687-697

23. Raggi C, Factor VM, Seo D, Holczbauer A, Gillen MC, Marquardt JU, Andersen JB, Durkin M, Thorgeirsson SS: Epigenetic reprogramming modulates malignant properties of human liver cancer. Hepatology 2014, 59:2251-2262

24. Sia D, Losic B, Moeini A, Cabellos L, Hao K, Revill K, Bonal D, Miltiadous O, Zhang Z, Hoshida Y, Cornella H, Castillo-Martin M, Pinyol R, Kasai Y, Roayaie S, Thung SN, Fuster J, Schwartz ME, Waxman S, Cordon-Cardo C, Schadt E, Mazzaferro V, Llovet JM: Massive parallel sequencing uncovers actionable FGFR2-PPHLN1 fusion and ARAF mutations in intrahepatic cholangiocarcinoma. Nat Commun 2015, 6:6087

25. Petta S, Valenti L, Marra F, Grimaudo S, Tripodo C, Bugianesi E, Camma C, Cappon A, Di Marco V, Di Maira G, Dongiovanni P, Rametta R, Gulino A, Mozzi E, Orlando E, Maggioni M, Pipitone RM, Fargion S, Craxi A: MERTK rs 4374383 polymorphism affects the severity of fibrosis in non-alcoholic fatty liver disease. J Hepatol 2016, 64:682-690

26. Bonacchi A, Romagnani P, Romanelli RG, Efsen E, Annunziato F, Lasagni L, Francalanci M, Serio M, Laffi G, Pinzani M, Gentilini P,
Marra F: Signal transduction by the chemokine receptor CXCR3: activation of Ras/ERK, Src, and phosphatidylinositol 3-kinase/Akt controls cell migration and proliferation in human vascular pericytes. J Biol Chem 2001, 276:9945-9954

27. Rizvi S, Yamada D, Hirsova P, Bronk SF, Werneburg NW, Krishnan A, Salim W, Zhang L, Trushina E, Truty MJ, Gores GJ: A Hippo and fibroblast growth factor receptor autocrine pathway in cholangiocarcinoma. J Biol Chem 2016, 291:8031-8047

28. Rovida E, Di Maira G, Tusa I, Cannito S, Paternostro C, Navari N, Vivoli E, Deng X, Gray NS, Esparis-Ogando A, David E, Pandiella A, Dello Sbarba P, Parola M, Marra F: The mitogenactivated protein kinase ERK5 regulates the development and growth of hepatocellular carcinoma. Gut 2015, 64:1454-1465

29. Rovida E, Navari N, Caligiuri A, Dello Sbarba P, Marra F: ERK5 differentially regulates PDGF-induced proliferation and migration of hepatic stellate cells. J Hepatol 2008, 48:107-115

30. Raggi C, Correnti M, Sica A, Andersen JB, Cardinale V, Alvaro D, Chiorino G, Forti E, Glaser S, Alpini G, Destro A, Sozio F, Di Tommaso L, Roncalli M, Banales JM, Coulouarn C, Bujanda L, Torzilli G, Invernizzi P: Cholangiocarcinoma stem-like subset shapes tumor-initiating niche by educating associated macrophages. J Hepatol 2017, 66:102-115

31. Mathur A, Ware C, Davis L, Gazdar A, Pan BS, Lutterbach B: FGFR2 is amplified in the NCI-H716 colorectal cancer cell line and is required for growth and survival. PLoS One 2014, 9:e98515

32. Doukas J, Mahesh S, Umeda N, Kachi S, Akiyama H, Yokoi K, Cao J, Chen Z, Dellamary L, Tam B, Racanelli-Layton A, Hood J, Martin M, Noronha G, Soll R, Campochiaro PA: Topical administration of a multi-targeted kinase inhibitor suppresses choroidal neovascularization and retinal edema. J Cell Physiol 2008, 216:29-37

33. Palanki MS, Akiyama H, Campochiaro P, Cao J, Chow CP, Dellamary L, Doukas J, Fine R, Gritzen C, Hood JD, Hu S, Kachi S, Kang X, Klebansky B, Kousba A, Lohse D, Mak CC, Martin M, McPherson A, Pathak VP, Renick J, Soll R, Umeda N, Yee S, Yokoi K, Zeng B, Zhu H, Noronha G: Development of prodrug 4chloro-3-(5-methyl-3-\{[4-(2-pyrrolidin-1-ylethoxy)phenyl]amino $\}$ 1,2,4-benzotria zin-7-yl)phenyl benzoate (TG100801): a topically administered therapeutic candidate in clinical trials for the treatment of age-related macular degeneration. J Med Chem 2008, 51: $1546-1559$

34. Fletcher GC, Brokx RD, Denny TA, Hembrough TA, Plum SM, Fogler WE, Sidor CF, Bray MR: ENMD-2076 is an orally active kinase inhibitor with antiangiogenic and antiproliferative mechanisms of action. Mol Cancer Ther 2011, 10:126-137

35. Wang X, Sinn AL, Pollok K, Sandusky G, Zhang S, Chen L, Liang J, Crean CD, Suvannasankha A, Abonour R, Sidor C, Bray MR, Farag SS: Preclinical activity of a novel multiple tyrosine kinase and aurora kinase inhibitor, ENMD-2076, against multiple myeloma. Br J Haematol 2010, 150:313-325

36. Farshidfar F, Zheng S, Gingras M-C, Newton Y, Shih J, Robertson AG, Hinoue T, Hoadley KA, Gibb EA, Roszik J, Covington KR, Wu CC, Shinbrot E, Stransky N, Hegde A, Yang JD, Reznik E, Sadeghi S, Pedamallu CS, Ojesina AI, Hess JM, Auman JT, Rhie SK, Bowlby R, Borad MJ; Cancer Genome Atlas Network; Zhu AX, Stuart JM, Sander C, Akbani R, Cherniack AD, Deshpande V, Mounajjed T, Foo WC, Torbenson MS, Kleiner DE, Laird PW, Wheeler DA, McRee AJ, Bathe OF, Andersen JB, Bardeesy N, Roberts LR, Kwong LN: Integrative genomic analysis of cholangiocarcinoma identifies distinct IDH-mutant molecular profiles. Cell Rep 2017, 18:2780-2794

37. Javle M, Lowery M, Shroff RT, Weiss KH, Springfeld C, Borad MJ, Ramanathan RK, Goyal L, Sadeghi S, Macarulla T, El-Khoueiry A, Kelley RK, Borbath I, Choo SP, Oh DY, Philip PA, Chen LT, Reungwetwattana T, Van Cutsem E, Yeh KH, Ciombor K, Finn RS, Patel A, Sen S, Porter D, Isaacs R, Zhu AX, Abou-Alfa GK, BekaiiSaab T: Phase II study of BGJ398 in patients with FGFR-altered advanced cholangiocarcinoma. J Clin Oncol 2018, 36:276-282 